\title{
MEMÓRIA HISTÓRICA: O POLÍTICO COMO VOCAÇÃO
}

\section{HISTORICAL MEMORY: THE POLITICIAN AS A VOCATION}

Jussara Rezende Araújo ${ }^{1}$

\section{RESUMO}

Entrevista realizada com Francisco Deliberador Neto importante político paranaense que atuou como gestor em diversos órgãos públicos do Estado principalmente entre as datas de 1950-90. O gênero jornalístico entrevista foi eleito pela autora para divulgar seus estudos e pesquisas sobre as teorias de Maurice Halbwachs de que as lembranças não são simples reminiscências do sujeito que expõe sua memória, mas que nelas podemos ler visão de mundo, utopias e ideologias de um sujeito que também é representação de um quadro de ideias coletivas; ideias estas ancoradas pelas representações do presente, com vista para a construção de um futuro. O entrevistado ao transmitir sua memória expõe também um projeto político do grupo ao qual depositou suas expectativas e esperanças de futuro.

Palavras-chave: entrevista - transmissão de memória - visão de mundo

\begin{abstract}
Interview with Francisco Deliberador Neto important politician born in the state of Paraná who served as manager in several state government agencies especially between the dates of 195090. The gender journalist was named interview by the author to publish his studies and research on the theories of Maurice Halbwachs that memories are not simply remnants of guy who exposes his memory, but we read them worldview, utopias and ideologies of a subject representation which is also a framework for collective ideas, these ideas anchored by the representations of this in order to build a future. In transmit his memory also reveals a political group to which deposited their expectations and hopes for the future.
\end{abstract}

Keywords: interview - memory transmission - worldview

\section{Memória histórica: o político como vocação}

Se as imagens do presente fundem-se estreitamente com as lembrançasdopassado, eseasimagensparecememprestaràs lembranças sua substância, é porque nossa memória não é como uma tabula rasa.

(Maurice Halbwachs)

A entrevista que vamos apreciar a seguir com o ex-político paranaense Francisco Deliberador Neto é parte de um livro reportagem sobre memória e sociedade, livro este editado no ano de 2006, mas nunca publicado. Passados quase seis anos da entrevista vamos ver que a fala do entrevistado ainda encontra tradução na atualidade, pois pautada pelas teorias dos quadros sociais de memória de HALBWACHS (2006) vamos ver que a fala de quem rememora é a exposição de uma representação político-social orientada pelo presente.

1 Jornalista; Doutora em Ciências da Comunicação; Professora Adjunta III da Universidade Federal do Paraná - Setor Litoral. E-mail: jussara.araujo@ufpr.br. 
A questão norteadora da nossa pesquisa que resultou no livro-reportagem foi colher dados que poderiam contribuir para oferecer ao leitor notícias de um tempo em que a política era exercida por vocação. Por isto, nosso entrevistado escolhido foi o gestor público do tipo weberiano, o executor, por excelência, idealista, mas convicto.

Escolhemos a entrevista para tentar repassar ao leitor como são frágeis nossas instituições públicas em termos de ausência de poder real de quem administra, e como estão sujeitas aos comandos políticos, mas como o sujeito político por vocação "desconhece" estes dados e age como se estes dados fossem irrelevantes para o seu projeto de gestão.

As lembranças são visões de mundo de um presente com vistas a um futuro que o entrevistado acredita deva ser para todos. Lembranças carregadas de valores políticos, ideológicos, e quadros utópicos de uma coletividade. Halbwachs "integra o social na psicologia individual" e, ao mesmo tempo, "mostra que os fatos sociais não podem ser compreendidos sem apelo às reações que as representações coletivas suscitam no pensamento dos indivíduos.

A noção de identidade, estudada por Halbwachs rompe com as dicotomias entre indivíduo e sociedade, passado e presente, bem como entre ciência e prática social, estando a identidade tão associada à ideia de memória como esta última à primeira. $\mathrm{O}$ sentido de continuidade e permanência presente em um indivíduo ou grupo social ao longo do tempo depende tanto do que é lembrado, quanto o que é lembrado depende da identidade de quem lembra. Da mesma forma que a identidade, a memória também deixou de ser pensada como um atributo estritamente individual, passando a ser considerada como parte de um processo social em que aspectos da psique se encontram interligados a determinantes sociais. A memória deixou, portanto, de ser considerada como fenômeno individual, passando a elemento constitutivo do processo de construção de identidades coletivas.

Os conteúdos narrados pelo entrevistado revelam não apenas a cultura específica do entrevistado, mas pode oferecer ao leitor uma visão de mundo do grupo social a que pertence. Por isto é emblemático. E por isto, atua como aglutinador de um ponto de vista histórico-social. Aquilo que Lucien Goldmann designou de consciência possível. (ARAUJO, 1994)

Conforme estudos das teorias da comunicação e de lógica semiótica, para vermos o mundo como uma mensagem é preciso antes entender o imaginário político do sujeito que fala que é - na realidade - uma síntese daquilo que seu grupo político seleciona como utopia e elege como ideologia.

Deliberador é um burocrata assumido, que cultiva o típico estilo weberiano, da política como vocação. Por isto procuramos estimular o entrevistado para explicar sua práxis como gestor público e a argumentar em defesa das políticas públicas e bem-estar que reivindica para 
a sociedade brasileira e para a comunidade paranaense.

Francisco Deliberador Neto, paranaense de Sertanópolis, norte do Paraná, advogado - formando da turma de 1957 da Faculdade de Direito da Universidade Federal do Paraná UFPR.

Chiquito - como ficou conhecido nos meios políticos brasileiro principalmente do período que vai de 1972-1996 - foi companheiro de José Richa, Álvaro Dias, Roberto Requião, Mário Covas, e diversos outros políticos e prefeitos do Paraná e do Brasil. Atuou como gestor público no período que abrangeu o auge da ditadura (1973), passando pelo começo do fim do Regime Militar (1978), re-democratização do Brasil. (1983), encerrando sua carreira pública em 1996.

Começou sua vida política na adolescência como estudante militante atuando na União Londrinense dos Estudantes Secundaristas - ULES. Continua sua militância como estudante de Direito na UFPR e ingressou na vida política quando foi eleito prefeito de Ibiporã, município localizado próximo de Londrina. Assim começou sua carreira como gestor público em diversos órgãos estaduais como o Departamento de Trânsito - o DETRAN do Paraná; superintendente do Porto de Paranaguá onde se tornou conhecido por sua visão do tipo executivo pragmático que combate a corrupção e promove o bom atendimento ao público, como vamos ver aqui.

O político por vocação em vez de engrossar a corrente dos neo-populistas que endossam o escoamento do dinheiro público pelas grelhas do assistencialismo demagógico busca resgatar o protagonismo de um servidor público - sem dúvida - uma trajetória de vida pautada pela busca da eficácia administrativa em benefício do interesse coletivo.

Quando Deliberador assumiu a Prefeitura de Ibiporã em 1977 o pagamento dos salários dos servidores públicos municipais, do então INPS e FGTS estava em atraso há três meses e o orçamento da Prefeitura já estava comprometido por um ano. Para cada um cruzeiro de dívida havia menos de 10 centavos para pagá-la. Ao encerrar sua gestão seis anos depois deixou em caixa 41 milhões de cruzeiros. Fundou uma Companhia de Desenvolvimento, construiu o primeiro Centro Social Urbano do município com horta comunitária, quadras esportivas, área de lazer e espaço para reuniões de grupos de Idosos, Artesãos e Associação de Moradores. Deu ênfase a políticas sociais acabando com práticas assistencialistas. Construiu casas populares, creches e aumentou o número de vagas escolares obtendo ainda a diminuição da evasão escolar em 80 por cento.

Depois que acompanhou José Richa, para Curitiba assumindo a gestão do Departamento de Trânsito do Paraná, um então malversado DETRAN - Chiquito - como advogado - observou que o Departamento de Trânsito tinha uma linguagem própria, que os serviços eram altamente 
especializados, apesar de funcionar sob a ótica da cultura do mau atendimento. Constatou também que inúmeras Portarias e Resoluções sem uma sistematização transparente geravam medo por parte dos funcionários hierarquicamente inferiores justamente para gerar concentração de poder e mais morosidade nos serviços. Ele diagnosticou este dado como "criar dificuldade para gerar facilidade". Agiu como advogado e como gestor firmado em seu projeto político e sua real vocação para o trabalho executivo.

Chiquito começou sua vida de militante primeiro acreditando no trabalhismo, e - de fato foi um trabalhador; depois no MDB e PMDB manteve sempre a crença no trabalho como combate para um espaço de bem-estar social. Em 2006 Chiquito estava então com 75 anos - embora ainda marcado pela visão do jovem que acreditou que é possível mudar através de combates.

Afinal, o que acontece nos órgãos públicos: endemia sistêmica ou surto epidêmico? Nem tudo está perdido? Nas memórias do entrevistado vamos poder "ler" algumas respostas. Vejamos a entrevista.

Pergunta: Começamos pelo Porto de Paranaguá: quando assumiu o Porto em 1987 o órgão apontava um déficit de $\mathrm{Cz} \$ 320$ milhões, em apenas um ano obteve um superávit de Cz\$740 milhões, então, como superintendente do Porto não sofreu ingerência política?

Resposta: Os Portos - além da ingerência política - sofrem influência dos sindicatos, porque os sindicatos portuários são organizados em termos de estrutura política. Os sindicatos portuários têm um tipo de política de cobrar, de exigir, e eles se unem demais. Para se ter uma ideia, no Porto de Paranaguá nós tínhamos duas equipes grandes de trabalho, dois grupos, trabalhavam 12 horas por dia, sendo que um grupo começava a meia-noite e o outro meio-dia. Só que o trabalhador do grupo da meia-noite não entrava a meia-noite. Ele ia para o Porto a meia-noite e só começava a trabalhar as duas horas da manhã, então duas horas ele "comia". E ele não saia doze horas depois - saia 10 horas depois porque tinha que ir ao sindicato. Então ficava aquele intervalo que ninguém trabalhava. E por outro lado o trabalhador fazia de um jeito que ele sempre ultrapassava os limites de horas-extras que se podia fazer. E todo o mundo fazia "vistas grossas". Para resolver isto começamos a fazer três turnos: isto gerava mais emprego, ninguém iria ultrapassar as horas-extras, e o trabalhador só saia quando o outro chegasse e não haveria interrupção nos serviços. A implantação dos três turnos quase gerou uma greve nacional. Para você ver a capacidade de organização dos trabalhadores portuários. Mas não é uma organização para a melhoria das condições de trabalho; é simplesmente para não mexer no que já está consumado e tornar a gestão portuária obsoleta. É a luta de classe visível e concreta. Não se consegue fazer nada e tem sindicato para tudo. Por exemplo, você pega um carro que você vai exportar do Brasil pra fora. Você leva até a entrada do Porto e lá o seu motorista não pode entrar no cais, 
então tem um motorista do sindicato - que normalmente não sabe dirigir o veículo, mas só ele pode pegar o carro para levar ao armazém, já no armazém é um outro Sindicato e para levar do armazém e encostar no navio é outro, e dentro do navio ainda outro. É um absurdo. Na minha época (1992) tinha um cliente do Porto - uma exportadora de papel. O papel vai nuns rolos muito grandes e tem que ter equipamento especial para lidar com aquilo senão você rasga e estraga. A empresa tinha os funcionários especializados para o transporte, mas caso autorizássemos que estes funcionários entrassem no serviço o sindicato ameaçava com greve.

Pergunta: Então tem uma série de problemas nos Portos também de gestão dos serviços?

Resposta: Na época do café se - por exemplo - você armazenasse o café em um armazém ao ar livre o sindicato cobrava taxa diferenciada porque era ao ar livre; eles punham uma bolinha no chão se tivesse um declive já era outro preço porque não era nivelado, uns negocio mais absurdo no mundo. Então é muito difícil. A luta de classe está lá bem visível. Um carregamento de frango - diversas quando o guindaste estava bem alto deixavam cair a caixa. Arrebentava tudo e em minutos você não via mais nenhum frango.

Pergunta: Você observou se esta realidade acontecia em todos os Portos brasileiros ou internacionais?

Resposta: Acontece em todos os Portos brasileiros. O sindicato tem escrito mais ou menos 600 pessoas, só que trabalha apenas uns 200 , mas na hora de acertar o pagamento eles dividem pra 600.

Pergunta: Como fazem isto?

Resposta: Porque trabalham assim: hoje têm 10 que foram escalados pra trabalhar, só que não aparece 10 para trabalhar. Um fica doente, outro vai levar filho doente no serviço médico, etc, etc.

Pergunta: É um problema que emperra a gestão?

Resposta: É uma forma de gestão que retrata bem a ineficácia em termos de excelência na qualidade dos serviços e melhoria das condições de trabalho. Os sindicatos fornecem os funcionários, o usuário paga e o Porto gerencia. É um negocio de louco. E eles passam de pai para filho. O Sindicato fazia o mesmo empreguismo que faz a instância pública ainda em muitos setores. Cansei de ver lá no Porto situação onde o trabalhador queria se aposentar e queria deixar o filho no lugar. E agente não queria isto então o trabalhador não se aposentava. Você pode fazer uma aposentadoria compulsória, só que ficava mais caro do que se ficasse trabalhando. Tive que aposentar alguns e como na época a inflação estava muito alta só com os juros eu pagava os funcionários todos. 
Pergunta: Vamos pensar mais sobre este problema na gestão dos Portos. Isto chega mesmo a causar problemas nos serviços de exportação?

Resposta: Sim atrapalha. Eu me lembro uma vez de uma ocasião que tinha um pessoal querendo comprar eucalipto aqui do Brasil, mas o custo portuário era muito elevado e eles optaram pelo produto chileno.

Pergunta: Bom. Passemos agora para sua história de vida. Seu interesse de entrar para a política foi para mudar o quê?

Resposta: Para mudar aquela coisa dos serviços públicos, onde o sujeito que não faz também não quer que o outro faça. A disputa é para ver quem faz menos. Isto pra mim é fruto de ausência de políticas públicas e do sistema de bem-estar social conduzido apenas pelo assistencialismo. Nossos serviços de bem-estar social ainda estão comprometidos com o paternalismo, empreguismo e com as contradições entre os interesses particulares e os interesses de todos. Eu via e ainda vejo na militância política a possibilidade de mudança porque, veja Sertanópolis em 1931 quando nasci: um município rico, mas isolado. Naquela época não havia estrada de ferro. A abertura das estradas de ferro era feita pela Companhia de Terras. A estrada passava na região de Ourinhos e ia até Cianorte onde ela tinha suas propriedades. Foi a última estrada de ferro que ela fundou, e ela não ia dar essa boca para Sertanópolis: uma estação para irmos de trem à Londrina. Então dou este exemplo para mostrar justamente onde entra o político, o papel de um representante político no conjunto social. Fazer política para a construção da cidadania, de um sistema de bem-estar social para todos, mas que funcione efetivamente bem. Entrei na política para mostrar que não se faz política para levar vantagens. Eu me lembro no Detran do Paraná, um dia eu estava passando atrás do portão ouvi dois funcionários conversando sobre o diretor do Detran que tinha recém assumido, que era eu mesmo e diziam: "este indivíduo vai acabar com a nossa vida". Traduzindo este acabar com a nossa vida como acabar com o caixa dois, as famosas caixinhas. Mas - fazendo política com gestões administrativas mais modernas - fomos mudando na prática: melhores salários, incentivando e criando uma Associação dos Funcionários para valorização da profissão; melhoramos a comunicação interna, implantamos um restaurante subsidiado; transporte coletivo só para os funcionários; serviços de bem-estar social.

Pergunta: Ok. Vamos continuar falando da sua gestão no DETRAN. Quais outras mudanças implementou já que considera isto de modernização?

Resposta: Penso que a questão central foi o movimento nacional que fizemos para a mudança do Código Nacional de Trânsito. Uma mudança que durou 10 anos para ser realizada. Saímos do DETRAN com um novo código que só vimos implementado anos depois. Mas não foi só isto. Na questão do mal atendimento. Primeiro mudamos os prazos para expedição de documentos. Quando chegamos no DETRAN tinha um setor de atendimento ao público chamado 
de chiqueirinho porque era um grande salão com um quadrado no meio onde ficava alguns funcionários dentro e do lado de fora desse quadrado formavam-se enormes filas e não tinha um lugar que dissesse para quê eram as filas. Invariavelmente tinha gente que ficava até uma hora na fila, e quando chegava a vez da pessoa é que ela descobria que estava na fila errada. Logo nós diminuímos de um mês para 40 minutos a renovação da Carteira de Habilitação. Tinha também o problema do lacre. O lacre na placa do veículo só podia ser feito na origem. Se o lacre arrebentava no Rio de Janeiro e o carro era do Paraná o indivíduo ficava sem alternativa. Por isto vimos que os DETRAN tinham que ter canais de comunicação. Fizemos no Paraná a primeira reunião de diretores dos DETRAN do Brasil e passamos a legislar por Portarias até que conseguimos uma mudança no DENATRAN - o Departamento Nacional de Trânsito que agilizou muitos serviços de trânsito. Mesmo assim os Departamentos de trânsito sofrem por causa da ingerência política.

Pergunta: Também nisto o gestor público sofre pressões?

Resposta: Sofre e pega a fama de quem só sabe dizer não. Veja. Quando fui prefeito de Ibiporã criamos na prefeitura a sala do não, e a sala do sim que era a sala do vice-prefeito. No momento em que ele não podia resolver mandava para mim que dizia o não. No início fiquei como carrasco, como um indivíduo que não tinha sensibilidade. Lembro também quando estava na EMOPAR alguns correligionários foram pedir para que eu encaixasse lá um engenheiro que era amigo deles. Estávamos - naquela época - demitindo pessoal, pois o órgão estava inchado, estava sobrando gente - como é que podia encaixar outro indivíduo lá dentro? Então disse não, e saíram dizendo que eu não tinha sensibilidade política. O gestor público na minha visão é também alguém que deve estar todo momento driblando as pressões.

Pergunta: Chegamos então novamente no problema da ausência de cidadania por parte de grande parte da militância política. Como fazer para atacar este problema?

Resposta: Aumentando o nível de instrução e informação da população.

Pergunta: E como você vê a privatização de serviços como a administração de estradas de rodagem por exemplo?

Resposta: Eu sempre fui contra, queria mostrar que a administração pública poderia ser tão eficiente quando a administração privada. Mas é difícil você achar quem vai administrar a coisa pública com condições emocionais de realmente se portar como um gestor. Normalmente quem vai administrar é o político de carreira e não necessariamente o político cidadão. A grande maioria dos cargos de diretores das empresas públicas é ocupado por pessoas que vão fiscalizar os interesses do grupo político majoritário. A indicação é feita pelo famoso consenso político. Normalmente é um fracassado na administração privada, um cabo eleitoral. E fazem uma 
carreira política em cima de uma administração pública: atendem reivindicações particulares, pessoais de deputados, da própria clientela do grupo local que exige, cobra, pressiona. Vira uma espécie de rainha da Inglaterra.

Pergunta: E o Legislativo o que fazer com os vereadores?

Resposta: Realmente, o vereador hoje não exerce a função dele de fiscalizar, legislar para o bem-estar de sua representação com princípios universais. A maioria hoje fica "tucanando" o prefeito, além do fato de que o número de vereadores está acima da necessidade em grande parte dos municípios. O mesmo com relação ao número de deputados federais, mais de 500. Eles não têm nem tempo útil para falar no plenário. Fazem trocas de favores. Tornam-se os mercadores que vão comprar o voto a troco de benefícios que vão obter para o núcleo do eleitorado deles. O legislativo hoje se transformou num mercado. Você chega à Assembléia e tem uma ambulância e para quê se existe uma Secretaria que tem esta função no Estado que é a Secretaria da Saúde! A função do político é levar educação política aos cidadãos. É trabalhar junto com seu núcleo e sua sociedade para solucionar problemas e não obter vantagens pessoais, e eleitorais. Para mim política é uma arte porque é uma forma de construção coletiva que envolve múltiplas concepções.

Pergunta: Na sua concepção o que fazer para o Brasil crescer para todos?

Resposta: Nós precisamos vender mais do que comprar e a gente compra muita porcaria. E até o que não devíamos comprar. Eu já vi o Brasil comprando milho. Bom, nós podemos produzir milho suficiente. Quer dizer, falta planejamento estrutural e estar sempre produzindo novos diagnósticos, mais atualizados com serviços auto-sustentáveis. E planejamento a longo prazo. Infelizmente o Brasil optou por rodovias. Funciona bem, mas é um serviço caro. Quando estava na Secretaria de Estado dos Transportes levantamos a idéia das linhas ferroviárias e fluviais. Encontramos uma dezena de bons projetos nas gavetas, mas foi impossível executá-los. Ainda em termos de sua pergunta temos o problema da falta de uma discussão sobre o nosso Estatuto da Terra. E ainda a falta de controle da população sobre os atos político-administrativos, não há transparência nos gastos realizados em relação ao que se arrecada e, por fim, o excesso de impostos.

Pergunta: Como você atacaria estes problemas?

Resposta: O problema da terra atacando primeiramente o atendimento aos cidadãos que precisam trabalhar e não encontram frentes de trabalho. Nosso planeta sofre com o desmatamento descontrolado e o Brasil devia instalar frentes de trabalho no campo nas áreas públicas como beira de estradas, plantarmos frutas, arborização em massa, cada fazendeiro pode e deve doar um pedaço de suas terras para um reflorestamento das margens de rios e estradas. Inúmeras 
obras poderiam ser feitas através de frentes de trabalho. E podemos dar títulos de uso da terra. Quanto ao problema do controle sobre as ações do Estado por parte da sociedade - penso que deveria ser feito com objetivos de fiscalizar e pressionar a administração pública no sentido do controle dos gastos, coibir a corrupção através do desmanche do consenso político, promover ações populares e civis públicas. Devíamos ainda cortar os privilégios do político funcionário público com um número excessivo de dias para afastamento remunerado para campanha política. Tem também a questão de termos mais flexibilidade na administração financeira já que as gestões administrativas passam por fluxos diferenciados de demandas internas e isso exige uma flexibilidade de contratação de profissionais. E com relação aos impostos: outro dia li que 31 por cento do custo de um produto é constituído de imposto. E pior, o item que mais pesa é o do alimento. Uma família com renda mensal de $\mathrm{R} \$ 2.500,00$ paga de imposto 29 por cento do que recebe. Significa que dos 12 meses do ano, o brasileiro trabalha quatro meses e meio para o fisco. Este quadro é desalentador, apesar de termos melhorado muito depois de 1994.

Pergunta: Em sua opinião como podemos mudar mais?

Resposta: Penso que o primeiro passo é um grande movimento político para exigirmos a formação de um processo Constituinte. Uma constituinte pura - quer dizer - com representantes eleitos só para fazer a Constituição.

Pergunta: Este é o seu lado político conte um pouco de como começou a militância e entrou para a política.

Resposta: Comecei quando vim para Londrina fazer o ensino médio. Na União Londrinense dos Estudantes Secundaristas - a ULES. Depois vim para Curitiba fazer Direito. Na época tinha duas alternativas: a primeira era cursar Odontologia porque a maioria do meu grupo de Londrina queria ir para Federal pra fazer este curso. Nós éramos um grupo de 19 militantes muito unidos. Mas sempre gostei de Direito e vivia sempre discutindo administração pública, grêmio, partido político.

Pergunta: Como foi sua travessia para a Capital?

Resposta: Sai de Londrina para Curitiba de trem para participar de um Congresso Estudantil, da União Paranaense dos Estudantes Secundaristas. Tinha estudantes de Londrina, de Paranaguá. Lembro-me de que quando saímos de ônibus da Ferroviária passamos pela Praça Rocha Pombo onde estava havendo um comício do pessoal ligado ao Getúlio Vargas e quem estava falando era o Vieira Lins que foi eleito deputado federal pelo Paraná. Lembro-me bem das palavras dele dizendo que "tiraram o Getúlio do poder, mas não tinham tirado o poder de Getúlio" e depois Getúlio se reelegeu presidente, através de eleição democrática. Foi quando me filiei ao PR, Partido Republicano e o nosso grupo se engajou na campanha apoiando o Bento Munhoz 
da Rocha Neto para governador. O Grupo do norte do Paraná era unido, mas em Curitiba, na União Paranaense dos Estudantes - a UPE - já era diferente. Tinha uma diversidade enorme. E quando cheguei na UPE cheguei com aquele espírito do PTB, de Getúlio. O pessoal que estava contra o Getúlio era da UDN e todo o pessoal articulado com os Estados Unidos por trás dos panos. Trabalhavam pelo Brigadeiro Eduardo Gomes. Mas nesta época da UFPR também fui presidente do PAR - Partido Acadêmico Progressista.

Pergunta: Passando um pouco para frente: como foi a trajetória até se eleger Prefeito de Ibiporã?

Resposta: Eu fui candidato em Sertanópolis e perdi. Depois meu pai mudou para Ibiporã. Fui candidato novamente e perdi. Eu sempre fiz uma campanha diferente, sem gastar dinheiro porque eu acho que o candidato está se dispondo para trabalhar para os outros. Sempre fiz pouco material de propaganda porque era mais na garganta mesmo, de casa em casa. Fazia reuniões, marcava em uma casa e com os vizinhos. Batia um papo com eles e isto foi progredindo. Até que chegou o golpe de 64 .

Pergunta: Como foi?

Resposta: Eu estava em Belém, no Pará trabalhando como advogado em uma empresa de regularização fundiária. Então veio o golpe de 64. Foi um estrago em termos de democracia, e passamos a ter apenas dois partidos: ARENA e MDB. Mas dentro da ARENA também havia oposição. Então quando voltei para Ibiporã me convenceram a sair candidato pela ARENA porque pelo MDB eu não poderia nem pensar em ser eleito. Esta eleição eu perdi. Depois disto fomos formando o MDB em Ibiporã e então fui eleito pelo MDB. Na época foram eleitos 35 prefeitos do MDB no Brasil e ainda a ditadura prorrogou os mandatos. Fiquei seis anos na Prefeitura numa época em que os governadores eram atrelados à ditadura e deixavam a oposição a pão e água, principalmente nós aqui do norte do Paraná: Londrina, Ibiporã, Cambe e Sertanópolis. Mas fomos nós que começamos a luta que culminou com a eleição de José Richa para o governo do Paraná.

Pergunta: A Prefeitura de Ibiporã foi um susto?

Resposta: Quando eu entrei na Prefeitura também era verde politicamente. Nunca tinha atuado em termos de gestão da coisa pública, era tudo novidade e naquela época nós entrávamos em março, dia 15. O prefeito anterior tinha dois meses e meio para gastar o orçamento do ano. Então quando entrei a Prefeitura tinha uma receita de 12 milhões e seiscentos e o prefeito anterior já tinha comprometido 10 milhões para o pagamento de funcionários que estava em atraso, mais uma dívida de 16 milhões. Tínhamos uma inflação problemática na época e problemas com contribuintes que não pagavam. Primeiro foi o corte de pessoal. Criei uma política para 
a demissão através de acordos indenizatórios e enxuguei 100 funcionários rapidamente, criei frentes de trabalho através de mutirões. Cortei o cafezinho. Criei uma Companhia de Desenvolvimento. Aumentamos a receita prestando serviços. Para nós a Prefeitura não pode fazer nada sem cobrar e dinheiro público só pode ser usado nas coisas de utilidade pública. E fiz todo o serviço de saneamento básico do município através da criação de uma Companhia de Desenvolvimento.

Pergunta: No final do seu mandato o José Richa é eleito pelo PMDB e você então é convidado por ele para administrar a EMOPAR e quais outros órgãos?

Resposta: Primeiro fui para a EMOPAR, depois para o DETRAN. Quando o Álvaro Dias assumiu em 1987 fui para o Porto de Paranaguá. Fiquei três anos no Porto e no último ano do Álvaro Dias - no começo de 1990 assumi a Secretaria dos Transportes. Depois que o Requião entrou voltei para o DETRAN. Fiquei mais dois anos até que pedi demissão e resolvi deixar a administração pública. A coisa estava saindo daquilo que almejávamos.

Pergunta: Bom. Então vamos agora falar um pouco mais do Porto de Paranaguá. Na época em que esteve lá você tentou fazer algo em termos de melhorias das condições vida dos entornos? Resposta: Olha, eu tentei. Conseguimos muito em termos de melhorar o atendimento, agilizar no sentido de não deixar os navios por muito tempo esperando. Quando eu assumi o Porto já era então o maior porto do sul do Brasil, atuando principalmente na exportação de grãos e sendo também utilizado pelo Paraguai para transporte de sua carga da alfândega, conforme um tratado com o Brasil. Firmamos o primeiro acordo coletivo de trabalho entre a administração e os portuários vinculados ao sindicato dos empregados Portuários do Estado do Paraná. O primeiro acordo em 54 anos que abriu a mesa de negociações aos trabalhadores do Porto. A pauta do acordo foi discutida por uma comissão paritária e com isto o Porto implantou o Plano Único de Cargos e Salários, além de creches para as funcionárias, melhoria do valor do seguro de vida, licença remunerada de cinco dias e uma nova contagem no adicional por tempo de serviço. Foi uma luta para chegar a este resultado. Também enquanto eu estive lá não aceitamos a manipulação das empreiteiras nas licitações; demitimos funcionários corruptos, promovemos a autosuficiência das operações portuárias; o contrabando de produtos agrícolas, em especial a soja, não havia. Também conseguimos realizar a manutenção e ampliação do cais e a construção de mais armazéns.

Pergunta: Você ganhou o apelido de Xerife.

Resposta: Eu já tinha este apelido. Tinha também o apelido de Munheca.

Pergunta: O que você acha que deixou de fazer no Porto de Paranaguá?

Resposta: Tentei fazer um serviço de bem-estar social na zona portuária, tentei estabelecer uma 
relação mais estreita com a cidade. Mas neste sentido não obtive eco das elites da cidade. Para estes setores o superintendente estava acabando com os privilégios e diziam que era uma pessoa que não conhecia a realidade do município. Na realidade não se trata disto e até hoje o Porto de Paranaguá é um corpo estranho dentro de Paranaguá. Deveria trazer mais benefícios sociais para a cidade, não importa a figura do gestor que lá está. O Porto não consegue ainda cumprir o seu papel social.

Pergunta: Como você lê o cenário da gestão pública hoje?

Resposta: Acho que os gestores públicos têm uma missão: implementar ações que façam o cidadão ver que tem gente séria na política. Que não se faz política para levar vantagem, mas pelo contrário, muitas vezes as consequências são graves. Algumas ações onde mesmo aquele que é contra vai continuar do contra, mas não por picuinha, mas porque acha que pode fazer melhor, com menor custo, com vantagens para todos. Esta mentalidade hoje é difícil da gente encontrar porque existe muita vaidade no sentido de ser querido, de ser bem visto, de ter um ibope alto na sua administração. Uma grande maioria acaba seduzida por essas ideias e quase ninguém tem a paciência de aguardar isso no final, porque é um resultado que você também não sabe se vai ter, é demorado. Há um imediatismo que acaba atropelando o sistema de bem-estar social como um todo.

\section{Referências}

ARAUJO, Jussara. A dialética da comunicação: o conceito de consciência possível de Lucien Goldmann. Mestrado em Teoria e ensino da comunicação. Faculdade Metodista de S.Bernardo do Campo, 1994.

BOSI, Ecléa. Memória e sociedade: lembranças de velhos. São Paulo: T.A.Queiroz/EDUSP. 1987.

ELIADE, Mircea. Imagens e símbolos: ensaio sobre o simbolismo mágico-religioso. São Paulo: Martins Fontes, 1996.

HALBWACHS, Maurice. A memória coletiva. São Paulo: Centauro, 2006.

Les cadres sociaux de la mémoire. Paris: Presses Universitaires de France, 1925. 